\title{
Designing a Business Model for Online Education Resources and e-Learning Implementation in a Developing Country: Case of Tanzania
}

\author{
Patrick .D. Kihoza ${ }^{1 *}$, Irina Zlotnikova ${ }^{2}$, Joseph Kizito Bada ${ }^{3}$, Khamisi Kalegele ${ }^{1}$ \\ ${ }^{1}$ Nelson Mandela African Institution of Science and Technology, Arusha, Tanzania. \\ 2 Botswana International University of Science and Technology, Palapye, Botswana. \\ ${ }^{3}$ Makerere University Business School, Kampala, Uganda. \\ * Corresponding author. Tel.:+255 71355 1987; email: kihozap@nm-aist.ac.tz \\ Manuscript submitted August 11, 2015; accepted December 15, 2015. \\ doi: 10.17706/ijeeee.2016.6.1.27-39
}

\begin{abstract}
This paper presents a business model for the ICT in education projects implementation. Using a design-research approach, we analyzed cases of the Online Resources and eLearning Implementation (OREI) framework that we developed. After the theoretical background, we discussed the proposed framework and a set of steps to guide the implementation. We formulated the framework practices and the levels of implementation precedencies using Matlab tools, and used Unified Modeling Language (UML) artifacts to present a business model for planning, implementation, and evaluation for the framework. A total of seven key components of 1) Government support, 2) infrastructures deployment, 3) technology enhancement, 4) training and recruitment of users and experts, 5) policies and guidelines, 6) stakeholders' participation, and 7) the monitoring and evaluation for acceptability, performance, and usability were discussed. Finally, we present a conceptual block diagram of the OREI framework business model to illustrate its validity on the enhancement of the ICT projects in education.
\end{abstract}

Key words: E-learning planning, online education resources, business model, digital contents, Tanzania.

\section{Introduction}

In today's complex world of rapid technology change and information overflow, a solid approach for technology and infrastructure deployment in the education system is essential. Such an approach helps ensure that technology, infrastructures, manpower recruitment, policies and guidelines implementations are consistent with the education objectives, and can be effectively utilized once the technology has been deployed [1]. Many ICT in education projects in developing countries have not been performing constructively [2]-[5]. However, resources (e.g. hardware, software, connectivity) are provided and beneficiaries trained; evaluation stages reported narrow usage of ICTs in classrooms and lack of additional competencies among the beneficiaries [1], [3], [6]-[9]. Most of ICTs projects carried out in Tanzania focused on improving teaching and learning practices and increased access to digital resources in secondary schools [3], [5], [10], [11]. In relation to ICT equipment in secondary education, the issues of planning, implementation, and evaluation of the performance, usability, and standardization are important considerations and raise concerns about the subsequent provision of effective systems [12]-[14]. The worst practices related to the use of ICTs in education in mots developing countries are dumping hardware in 
schools without prior usage planning, transferring ICT-related models and practices from developed countries to the less developed education systems, deploying hardware without pedagogical contents being planned and the lack of monitoring and evaluation [15], [16]. The more diverse the level and range of ICT equipment configurations schools can have the more complex and expensive technical support solution will need to be to support them. A more centrally reinforced technology deployment approach, where the specifications for new infrastructures and the level of technology to use have to be planned, standardized, and more complemented by appropriate local experts', would prevent many of these concerns. There is a need to have an integrated framework business model that guides existing policies and frameworks for the ICT in education enhancement.

\section{Background}

\subsection{Technology and Education Paradigm Shifts}

Education paradigms are shifting to include online learning, hybrid learning, and collaborative models. The use of ICT as a pedagogical tool has the power to support and reshape education both in the classroom and beyond the school walls [17]. ICT makes educational contents easier to find, to access, to manipulate and remix, and to disseminate. The pedagogy of literacy with ICT across any curriculum encourages movement from ICT as supplementary tools to a model that infuses ICT across the curriculum [18]-[21].
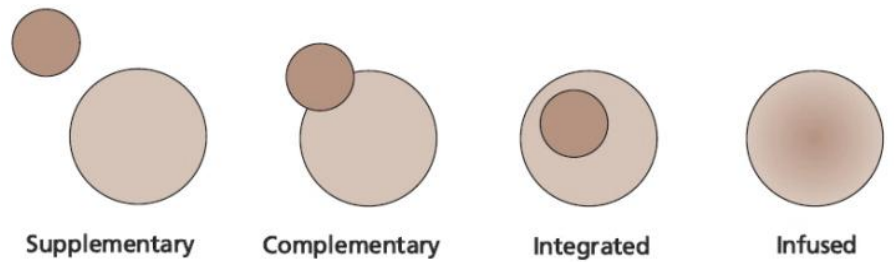

Fig. 1. Relationship between ICT and curriculum [20].

A supplementary relationship separates ICT and curriculum in space, time, and personnel-separate computer labs, computer classes, and computer teachers. A complementary relationship when there are ICT connections with curriculum in various ways. An integrated relationship allows the classroom teacher to bring ICT into the classroom so it is available at teachable moments. An infused relationship allows the transparent application of ICT, wherever and whenever appropriate, to enhance critical and creative thinking. The ICT teacher training efforts could be classified into four categories such as ICT as part of content, ICT as a facilitator, ICT as a core delivery and ICT as content both contributing to the ICT as a core component in teacher education and its application.

There are trends of technology changes that have forced many education systems worldwide to change. Examples of important technological trends identified in several studies are:

1) Cloud computing- is an evolving new computing model for providing computing services that relies on a number of present technologies (e.g., the Internet, virtualization, grid computing and Web services) [22]. It has transformed education systems through computing and communication, data storage and access, and collaborative work [23]. The application and services of cloud computing to schools are such as remote access to learning tools in a cost effective manner to the school systems [24].

2) Mobile learning is becoming an integral part of secondary education practices, increasingly common for students to own and use portable devices in many countries where policies and teaching approaches support [25], [26]. Personal mobile technologies for learning are more widespread (Personal Digital Assistants, tablet or smartphone); with easy to use and touch screen interfaces they 
are gateways to endless learning, collaboration, and productivity fostered by the Internet [27], [28].

3) Learning analytics are more associated with deciphering trends and patterns from educational big data, or huge sets of student-related data, to further the advancement of a personalized, supportive system of elementary education [29], [30]. It is the measurement, collection, analysis and reporting of data about learners and their contexts, for purposes of understanding and optimizing learning and the environments in which it occurs [23], [25].

4) Open content they focuses on sharing of significant amounts of curricula, resources, and learning materials [25]. In many parts of the world, open content represents a profound shift in the way students study and learn by providing open data, and open resources, along with notions of transparency and easy access to data and information easily accessible via the internet [31]-[33].

5) Virtual and remote laboratories take advantages of the wireless networks, mobile devices, and cloud-based software to make scientific experiences more accessible for schools that lack fully equipped labs [34]. In in virtual and remote environments, an experiment can be conducted several times with greater efficiency and precision [25].

6) Social media have changed the way people interact, present ideas, and information, and communicate. Educators, students, and even the public routinely use social media to share current events, opinions, and articles of interest [35]-[37]. The fact that all of these various groups are using social media speaks to its effectiveness in engaging people [38].

\subsection{Critical Challenges Leading to Education Reform}

There are challenges that inspired the need for education systems to change. They also have influenced the need for framework to guide the planning, implementation and evaluation of the ICT investments in education based projects. Present and future challenges that hinder technology use in education are:

1) Teachers' efforts and ambitions to integrate new technologies in classrooms and curriculum implementation have changed [39], [40]. The extent to which teachers and their learners have access to digital educational resources at school and at home, have influenced teaching and learning experience to change [41], [42]. The results are that the new investments are underutilized, not used at all, or used in a way that mimics an old process rather than innovating new processes that may be more engaging for students [23].

2) Old and traditional practices and approaches limit broader uptake of new technologies. In many cases, experimentation with, or piloting of innovative applications of technologies are often seen as outside the role of teachers, and thus discouraged [6], [43], [44]. Students are different, but schools are still using materials developed decades ago, but today's students come to school with very different experiences due to globalization and information overflows [45], [46]. Changing these processes will require major shifts in attitudes as much as they will in policy.

3) New models of education are bringing unprecedented competition to traditional models of schooling. This is a concern, as where schools' access open education resources (e.g. multimedia, games, lectures, and tutorials) providing an important part of the learning process [47], [48]. Socio-economic aspects are significant causes of differed digital educational resources access [23]. Open educational resources (e.g. MOOCs) have opened the doorway to entirely new ways of thinking about online learning.

4) The increased blending of formal and informal learning. Traditional approaches are running short when without technology mix; access to online resources is becoming more demanding than ever [23]. New concepts and materials are initially studied outside of school, thus preserving class time to refine mastery with discussions, collaborations with classmates, problem solving, and experimentation [49]-[52]. 
The demand for personalized learning and learner centered demanded by the $21^{\text {st }}$ century education system is not adequately supported by current practices [25]. New learning models that are engaging to younger generations are more challenging [53]. New technologies that provide more learner choice and control and allow for differentiated instruction enlarged the gap between the vision and the tools needed to achieve the personalized learning [54]-[56].

\section{Purpose of the Study}

In developing countries, Information and communication Technologies (ICTs) are often seen as a promising solution to overcome educational systems deficiencies. However, ICTs solutions are normally expensive; it is a real challenge to use novel ICT based solutions in a meaningful way without prior strategic planning. For instance, in developing countries like Tanzania, deployment of ICTs in education has been spanned as shortcut; no ahead planning frameworks and policies that leads as roadmaps. Costly ICTs are being procured and some offered by development partners as donations without prior planning on how they are to benefit the education systems. The aim of this study was to contribute to the development of a technology supported pedagogical reform that uses a framework for planning, implementation, and monitoring and evaluation, that we called OREI (Online Resources and eLearning Implementation). The framework combined government support, training and recruitment, experts involvement, technology deployment, infrastructures enhancement, policy makers, beneficiaries, and other stake holders to be used in as a roadmap for transforming education with new technologies. The study asserts to why it is important to have a roadmap framework that consider involvement of multi-stakeholders in each stage when the government wants to deploy pedagogical ICTs in the education systems.

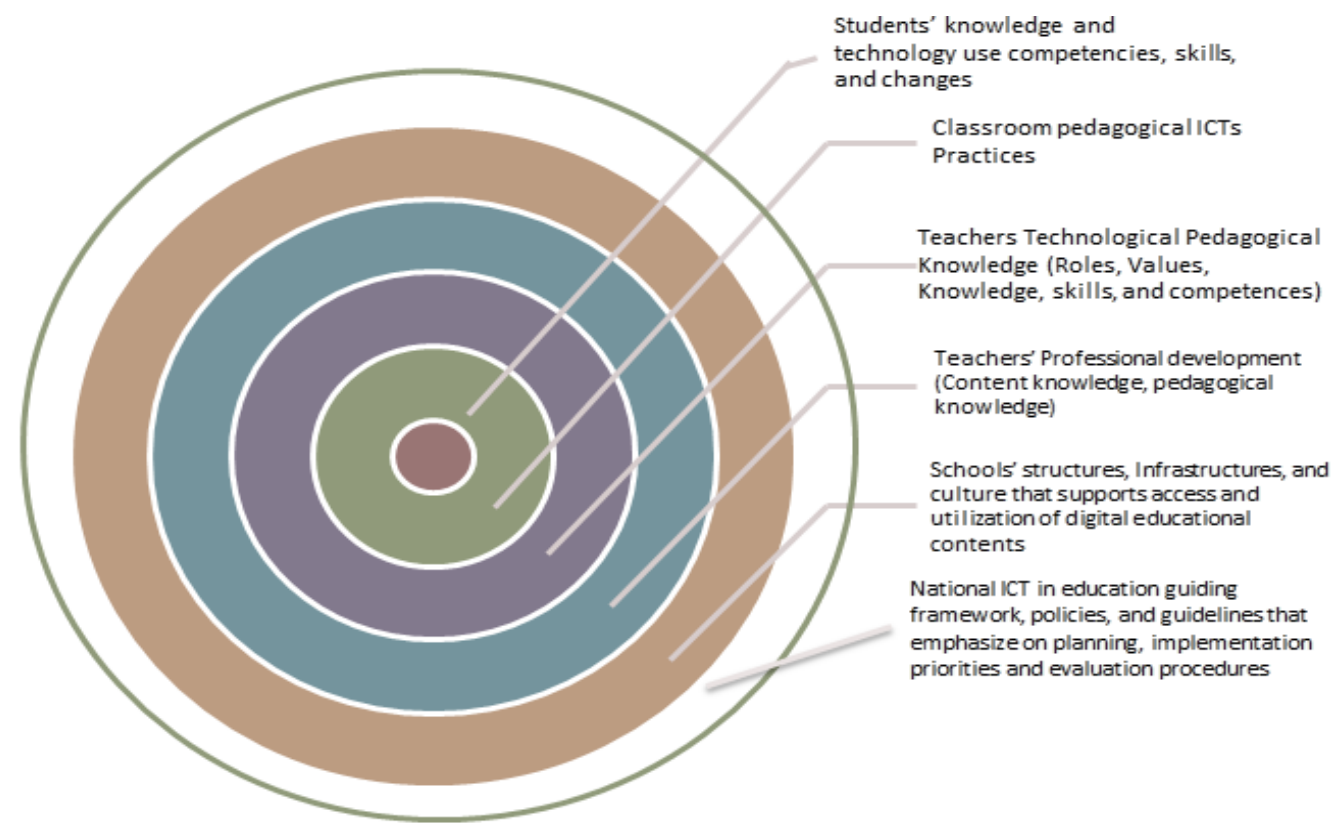

Fig. 2. Linking sustainable technology use in schools' with other aspects.

Fig. 2 above show the dependencies and causality effects between components that have to be considered when planning for technology use in the education system. The objective of our study is to design a novel guiding principle for pedagogical ICTs solutions enhancement. To solve local educational problems, the Framework for Online Digital Educational Resources Sharing and Blended Learning Implementation that we developed, could be used to guide the future planning, investment and evaluation of ICTs in education projects in developing countries, taking Tanzania as a show case study. 


\section{Methodology}

This was a design-based research for developing the OREI framework business model. Design based research is a methodology suitable to both research and design of technology-enhanced learning environments (TELEs) [57]. The framework addressed the need for innovation in educational contexts [58]. It focused on the challenges confronting technology innovations using usable knowledge implemented in real-world school contexts with a framework guiding systemic technology Innovations as an end result [59]. In this study, we followed steps were used:

1) First, developed interactions of the conceptual framework (OREI) components.

2) Second, we used Matlab tools to generate implementation alternatives based on interchanging the framework components.

3) The implementation alternatives were used to determine cases of the levels of precedencies when working towards realizing an optimum goal of any systems development ICT in education based project.

4) In the current work, we analyzed cases of the framework components based on the developed levels of precedencies samples.

5) Third, we designed a framework business model using Unified Modeling Languages (UML) artifacts as a result for this study.

\section{Planning Requirements for Online Digital Educational Resources Sharing and Blended Learning Implementation}

The framework developed puts Government intervention at the highest priority and evaluation as the final stage when planning for online digital education resources sharing and blended learning in secondary education. The interactions of components in Fig. 3 below were based on the cause effects between requirements of the framework.

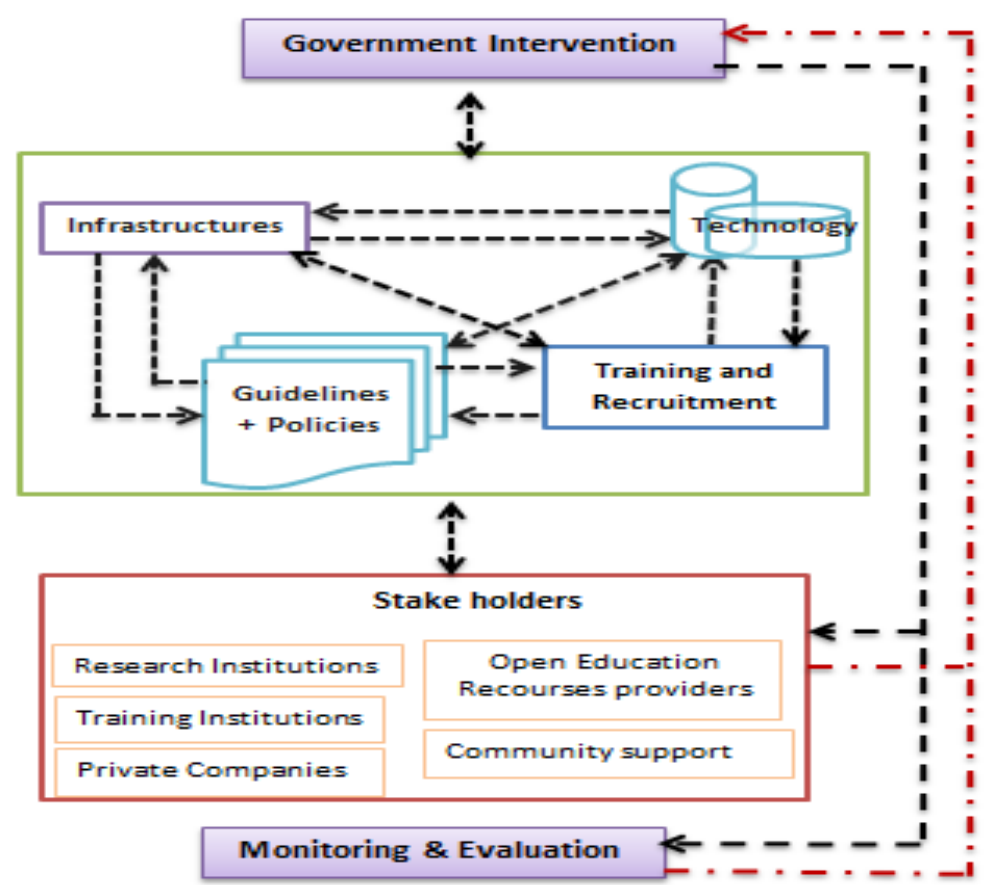

Fig. 3. A planning conceptual model for online educational resources and e-learning implementation.

The framework addressed seven key components that are must in order to achieve sustainability in ICT in education projects. Others are infrastructures (e.g. hardware, software, projectors, multimedia devices, 
internet connections, wireless access devices etc.), technology (Learning Contents Management Systems that could work as communication and collaboration space), recruitment, and Training (training teachers and students to be confident with infrastructures and the technology, hiring experts). In addition, Guidelines and Policies (e.g. Ethics issues and ICT, curriculum and syllabuses reviews so they can match with technology integration, teaching and training manuals, performance indicators and assessment procedures etc.) and stake holders (e.g. research and training institutions, the communities, etc.) Students' abilities and eager to learn using ICT tools can be influenced positively by the availability of relevant infrastructures in schools and the teachers knowledge, skills, attitudes and ICT use competences. In addition, training institutions can influence teachers' knowledge and pedagogical ICT tools competences through readiness to ICT use programmes and practices tutors are familiar with.

\subsection{Determining Framework Components Implementation Levels' of Precedencies}

The interactions in Figure 3 above could overlap and mostly each component depends on one another. Seven components were modeled. The following assumptions were made in implementing the framework levels of precedencies.

Assumption 1. In whatever case of the level of precedencies considered, the Government intervention must start, and the Evaluation activities must finalize the process.

Assumption 2. Depending on the Government support financially, materially and the availability of expertise, the component of Policies, Guidelines, Technology, Infrastructures and the stakeholders can be mixed during implementation. This should be determined by the SWOC analysis report.

Assumption 3. To model the possible levels of precedencies requirement components was serially labeled as:

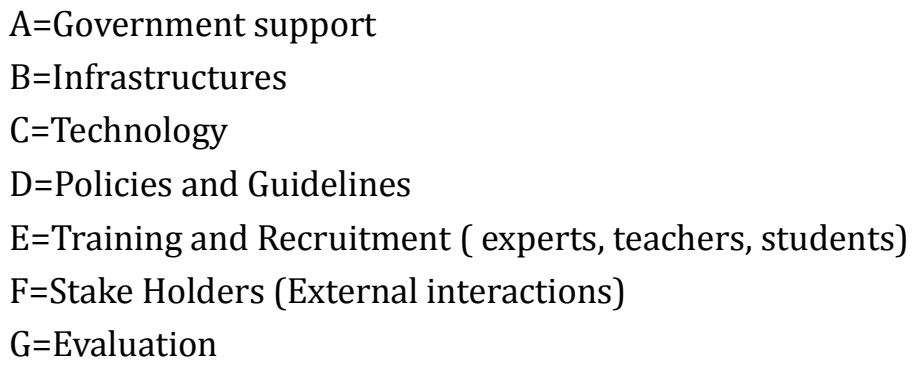

Using Matlab tools, we generated 120 numbers of possible levels of precedencies and implementation alternatives (see appendix). Within each of the levels of precedencies produced can regenerate more alternatives based on the SWOC analysis report. Presented in this study are nineteen examples for illustrations and generated operations tree figures. To be more specific, components grouped together in circles in the figures below could be carried out concurrently while all other components that are not grouped in circles are to be carried individually and separately. The randomly cases of the possible alternatives of the levels of precedencies are presented below:

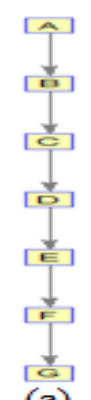

(a)

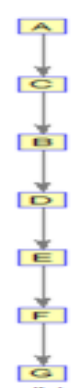

(b)

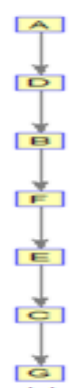

(c)

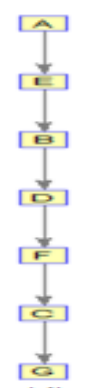

(d)

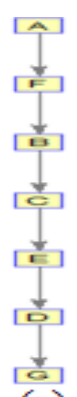

(e)

Fig. 4. Levels of precedencies and implementation alternatives performed serially. 


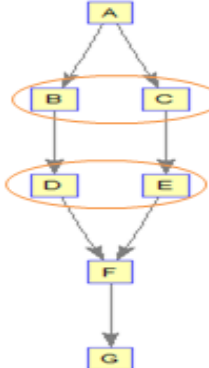

(a)

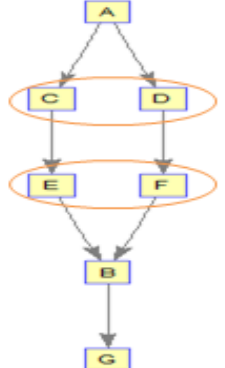

(b)

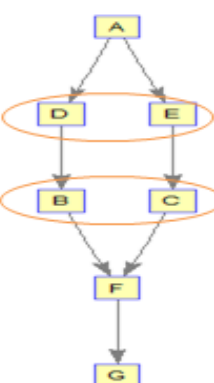

(c)

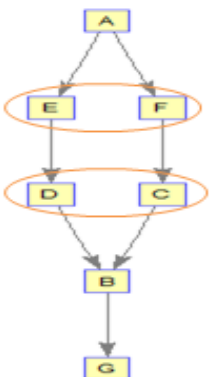

(d)

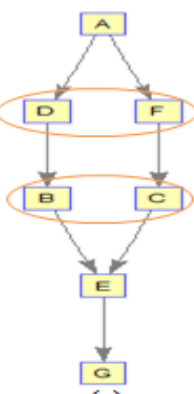

(e)

Fig. 5. Levels of precedencies and implementation alternatives with two activities and serially combined.

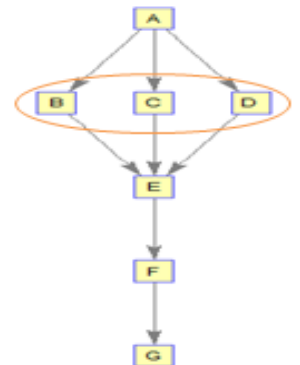

(a)

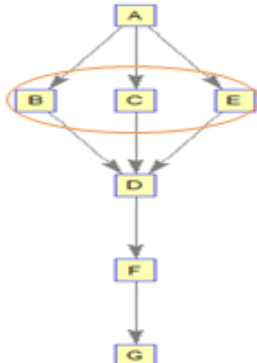

(b)

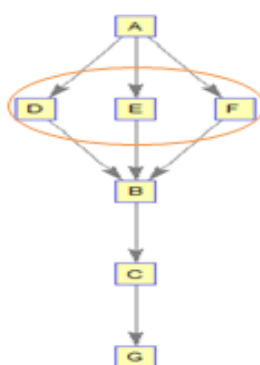

(c)

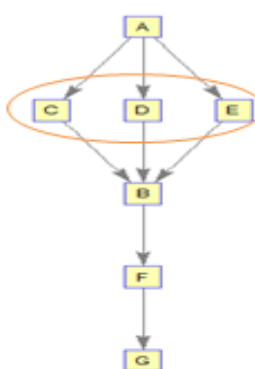

(d)

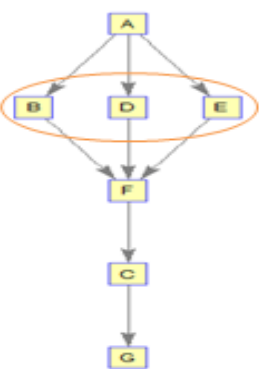

(e)

Fig. 6. Levels of precedencies and implementation alternatives with three activities and serially combined.

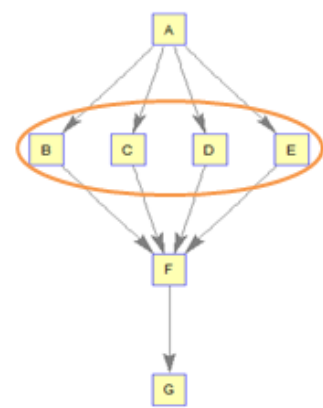

(a)

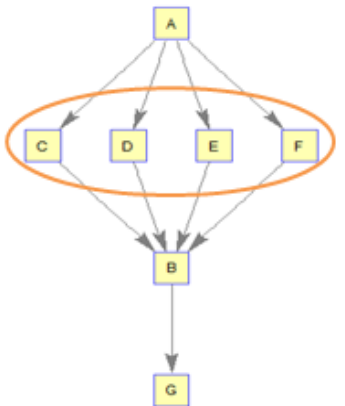

(b)

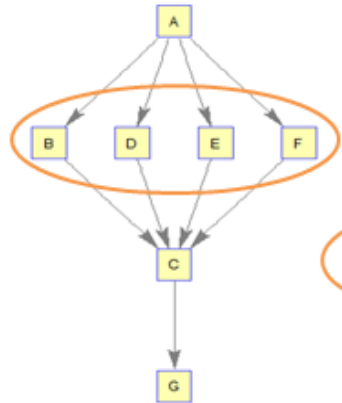

(c)

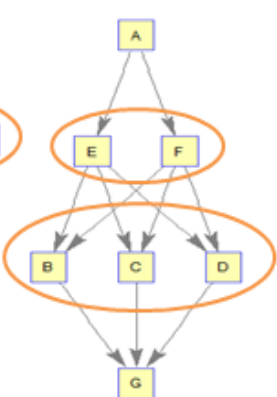

(d)

Fig. 7. Levels of precedencies and implementation alternatives with three activities and serially combined.

Table 1. Descriptions of the Levels of Precedencies Presented Above

\begin{tabular}{|l|l|}
\hline \multicolumn{1}{|c|}{ Fig. No } & \multicolumn{1}{|c|}{ Descriptions } \\
\hline $\begin{array}{l}\text { Fig. 4: (a, b, c, } \\
\text { d, and e) }\end{array}$ & $\begin{array}{l}\text { Considered carrying out each activity sequentially and separately. The levels of } \\
\text { precedencies during implementation could only be determined by carrying out SWOC } \\
\text { analysis. }\end{array}$ \\
\hline $\begin{array}{l}\text { Fig. 5: (a, b, c, } \\
\text { d, and e) }\end{array}$ & $\begin{array}{l}\text { Considered combining some activities in a pairwise followed by indivual activities that } \\
\text { could be performed sequentially and separately after getting inputs from previous } \\
\text { activities. The levels of precedencies during implementation could be determined by } \\
\text { Government budget and a SWOC analysis report. }\end{array}$ \\
\hline $\begin{array}{l}\text { Fig. 6: (a, b, c, } \\
\text { and d) }\end{array}$ & $\begin{array}{l}\text { Considered combining three activities at once followed by indivual activities that could be } \\
\text { performed concurrently after getting inputs from previous activities. The levels of } \\
\text { precedencies could only be determined by resources availability and a SWOC analysis } \\
\text { report. }\end{array}$ \\
\hline $\begin{array}{l}\text { Fig. 7: (a, b, c, } \\
\text { d, and e) }\end{array}$ & $\begin{array}{l}\text { Considered combining four activities followed by indivual activities carried out } \\
\text { concurrently after getting inputs from previous activities. The levels of precedencies could } \\
\text { only be determined using a SWOC analysis report. }\end{array}$ \\
\hline
\end{tabular}

\subsection{The Framework Business Model and Its Constructs}


It is self-evident that the establishment of pedagogical ICTs, broadband networks, centralized technology and supportive infrastructures (computer hardware and software) and other up-to-date teaching and learning technology is a priority area for secondary education investment. The ICT equipment currently available in few schools and teacher training colleges for use in the classroom is inadequate and much is outdated. It is not possible to create a blended e-learning culture and embed ICT in the curriculum without having appropriate and adequate information and communications technology tools available in the education systems. Within the rapidly changing world of information technologies, evaluation, renewal, and replacement of computers and outdated technologies are on-going requirements. Carrying out any of these kinds of projects needs carefully planning, implementation, and evaluation to avoid committing huge investments on unpredictable achievements; hence predefined business model is the solution.

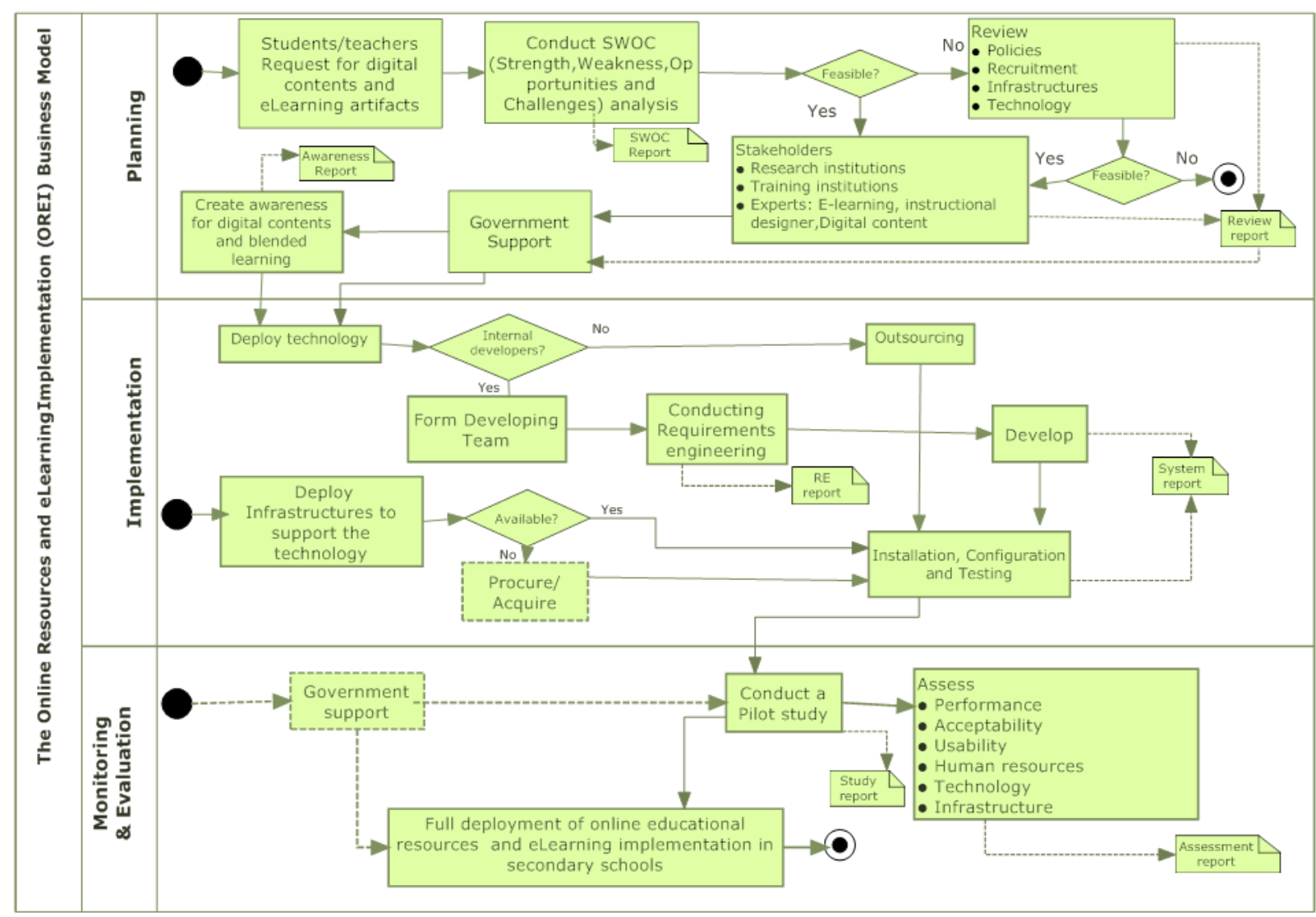

Fig. 7. Conceptual OREI framework business model.

Fig. 7 above is a roadmap to ICT deployment in secondary schools, as far as any planning involving technology is concerned, the flexibility to change or reinterpret goals is vital. The framework business model will assist developing countries, Tanzania as a case to plan for the effective use of digital technologies in schools to prepare students for the demands of an ever-changing world, to achieve powerful learning and teaching, and improve learning, teaching, avoid investing in outdated technologies and improve administration. When developing a plan based on this business model, there should be a vision to incorporate the direction that creates a picture of the future, how it looks, and how ICT could enable improvement. To achieve this, several resources must be identified in the SWOC (strength, weakness, opportunities and challenges) analysis report, which comes at every stage of planning and implementation of this business model.

\section{Conclusion}


The successful integration of ICT in public schools depends on a planned and harmonized approaches, involving experts of different professionals, beneficiaries, stakeholders from various institutions that are spearheaded by strong leadership at all levels. However, a government centralized funding support works, there is a potential controversial between funding of school ICTs, experts opinions, planning and decision-making [60]. Using a design-research approach, we analyzed cases of the framework design requirements, formulated levels of precedencies using Matlab tools, and used Unified Modeling Language (UML) artifacts of the framework activities to design a framework business model for planning, implementation, and evaluation of ICT in education projects called OREI (Online Resources and eLearning Implementation). The designed model addressed the positions and involvement of the government, manpower recruitment, experts, technology, infrastructures, policy makers, beneficiaries, and other stake holders. The designed model integrated leadership, time, investment, and policy imbued with vision to transform secondary education and building blended e-learning culture. Thus teacher professional development in the use of pedagogical ICTs should embody and model the forms of pedagogy that teacher can use themselves in their classrooms. A key lesson of previous initiatives[3], [5], [61], [62], demands governments in developing countries to have a predefined achievements before requesting for donor funding. In this study planning, committing an investment, evaluations and monitoring the sustainability of the planned and implemented ICT project are potential to the deployment of technology in schools.

\section{Appendix}

Possible Numbers of the Levels of Precedencies that determines implementation alternatives

Note: Below is the table showing 120 numbers of the levels of precedencies, however they are not necessarily to be undertaken serially. For example, for a set with "ABCDFEG", the set of "BC" can be taken together, "DF" can also be combined, "E" can separately be accomplished and finalize with "G"alone.

$A=$ Government support

$\mathrm{B}=$ Infrastructures

$\mathrm{C}=$ Technology

$\mathrm{D}=$ Policies and Guidelines

$\mathrm{E}=$ Training and Recruitment (experts, teachers, students)

$\mathrm{F}=$ Stake Holders (External interactions)

$\mathrm{G}=$ Monitoring and Evaluation

\begin{tabular}{|l|l|l|l|l|}
\hline ABCDEFG & ACBDEFG & ADBFECG & AEBDFCG & AFBCEDG \\
\hline ABCDFEG & ACBDFEG & ADBFCEG & AEBDCFG & AFBCDEG \\
\hline ABCEDFG & ACBEDFG & ADBCEFG & AEBFDCG & AFBDECG \\
\hline ABCEFDG & ACBEFDG & ADBCFEG & AEBFCDG & AFBDCEG \\
\hline ABCFDEG & ACBFDEG & ADBECFG & AEBCDFG & AFBEDCG \\
\hline ABCFEDG & ACBFEDG & ADBEFCG & AEBCFDG & AFBECDG \\
\hline ABDCEFG & ACDBEFG & ADCFBEG & AECDBFG & AFCBDEG \\
\hline ABDCFEG & ACDBFEG & ADCFEBG & AECDFBG & AFCBEDG \\
\hline ABDECFG & ACDEBFG & ADCBEFG & AECFBDG & AFCDBEG \\
\hline ABDEFCG & ACDEFBG & ADCBFEG & AECFDBG & AFCDEBG \\
\hline ABDFCEG & ACDFBEG & ADCEBFG & AECBDFG & AFCEBDG \\
\hline ABDFECG & ACDFEBG & ADCEFBG & AECBFDG & AFCEBG \\
\hline ABECFDG & ACEBFDG & ADEFBCG & AEDCBFG & AFDBCEG \\
\hline ABECDFG & ACEBDFG & ADEFCBG & AEDCFBG & AFDBECG \\
\hline
\end{tabular}




\begin{tabular}{|l|l|l|l|l|}
\hline ABEDFCG & ACEDFBG & ADEBFCG & AEDFBCG & AFDCBEG \\
\hline ABEDCFG & ACEDBFG & ADEBCFG & AEDFCBG & AFDCEBG \\
\hline ABEFDCG & ACEFDBG & ADECFBG & AEDBFCG & AFDEBCG \\
\hline ABEFCDG & ACEFBDG & ADECBFG & AEDBCFG & AFDECBG \\
\hline ABFCDEG & ACFBDEG & ADFECBG & AEFCDBG & AFEBDCG \\
\hline ABFCEDG & ACFBEDG & ADFEBCG & AEFCBDG & AFEBCDG \\
\hline ABFDCEG & ACFDBEG & ADFBCEG & AEFDCBG & AFECDBG \\
\hline ABFDECG & ACFDEBG & ADFBECG & AEFDBCG & AFECBDG \\
\hline ABFECDG & ACFEBDG & ADFCBEG & AEFBCDG & AFEDCBG \\
\hline ABFEDCG & ACFEDBG & ADFCEBG & AEFBDCG & AFEDBCG \\
\hline
\end{tabular}

\section{Acknowledgment}

We would like to acknowledge the support financially from The Nelson Mandela African Institution of Science and Technology, Arusha, Tanzania.

\section{References}

[1] Wims, P., \& Lawler, M. (2007, March). Investing in ICTs in educational institutions in developing countries: An evaluation of their impact in Kenya. International Journal of Education and Development Using ICT, 3(1), 5-22.

[2] Aduwa-Ogiegbaen, S. E. O. (2009). Nigerian inservice teachers' self-assessment in core technology competences and their professional development needs in ICT. Journal of Computing in Teacher Education, 26(1), 17-28.

[3] Andersson, B., et al. (2014, May). Evaluation of implementation of ICT in teachers' colleges project in Tanzania. Swedish International Development Cooperation Agency (Sida). Stockholm, Sweden.

[4] Brunello, P. (2010, July). ICT for education projects: a look from behind the scenes. Information Technology for Development, 16(3), 232-239.

[5] GESCI. (2011). Report on the review of modules, monitoring and evaluation tools and training of trainers project: Teaching and learning science, mathematics and English in secondary schools using ICT. Ministry of Education and Vocational Training (MoEVT)/GESCI.

[6] Hennessy, S., et al. (2010). Developing use of ICT to enhance teaching and learning in East African schools: A review of the literature. University of Cambridge and Aga Khan University Institute for Educational Development-Eastern Africa.

[7] Kessy, D., et al. (2006). The reasons for under use of ICT in education: In the context of Kenya, Tanzania and Zambia. Proceedings of Fourth IEEE International Workshop on Technology for Education in Developing Countries (pp. 83-87).

[8] Sánchez, J., \& Salinas, A. (2008). ICT \& learning in Chilean schools: Lessons learned. Computers \& Education, 51(4), 1621-1633.

[9] Sharma, R. C. (2003). Barriers in using technology for education in developing countries. Proceedings of International Conference on Information Technology: Research and Education (pp. 512-516).

[10] Hardman, F., et al. (2011). Developing a systemic approach to teacher education in sub-Saharan Africa: Emerging lessons from Kenya, Tanzania and Uganda. Compare: A Journal of Comparative and International Education, 41(5), 669-683.

[11] Swarts, P., \& Wachira, E. M. (2010). Tanzania: ICT in education situational analysis. Global e-Schools and Communities Initiative. 
[12] Davis, F. D. (1993). User acceptance of information technology: system characteristics, user perceptions and behavioral impacts. International Journal of Man-Machine Studies, 38(3), 475-487.

[13] Palmer, J. W. (2002). Web site usability, design, and performance metrics. Information Systems Research, 13(2), 151-167.

[14] Tsakonas, G., \& Papatheodorou, C. (2006). Analysing and evaluating usefulness and usability in electronic information services. Journal of Information Science, 32(5), 400-419.

[15] Trucano, M. (2010). Worst practice in ICT use in education. Edutech: A World Bank Blog on ICT Use in Education.

[16] Trucano, M. R., et al. (2011). Worst practices in ICT use in education, low-cost gadgets, e-books in Africa and a hole in the wall: Learning from the use of educational technologies in developing countries. The World Bank. Washington, DC.

[17] Wastiau, P., et al. (2013). The use of ICT in education: A survey of schools in Europe. European Journal of Education, 48(1), 11-27.

[18] Kafitz, D., \& Cauthen, L. (2013). Digital curriculum strategy for K12 schools. The learning Counsel-Research \& Context on the Shift to Digital Curriculum.

[19] Keeler, C. G. (2008). When curriculum and technology meet. Journal of Computing in Teacher Education, 25(1), 23-30.

[20] Manitoba Education. (2006). A continuum model for literacy with ICT: A resource for developing computer literacy. Manitoba, Canada.

[21] Pade-Khene, C. (2015). Curriculum development of an ICT4D module in the South African context. Issues in Informing Science and Information Technology, 12.

[22] Sultan, N. (2010). Cloud computing for education: A new dawn?. International Journal of Information Management, 30(2), 109-116.

[23] Johnson, L., et al. (2014). NMC horizon report 2014 K-12. The New Media Consortium. Austin, Texas USA.

[24] Stein, S., et al. (2013). Improving K-12 pedagogy via a Cloud designed for education. International Journal of Information Management, 33(1), 235-241.

[25] Johnson, L., et al. (2013). NMC horizon report 2013 K-12. The New Media Consortium. Austin, Texas USA.

[26] Lieberman, D. A., et al. (2009). Young children's learning with digital media. Computers in the Schools, 26(4), 271-283.

[27] Huizenga, J., et al. (2009). Mobile game-based learning in secondary education: Engagement, motivation and learning in a mobile city game. Journal of Computer Assisted Learning, 25(4), 332-344.

[28] Roschelle, J. (2003). Keynote paper: Unlocking the learning value of wireless mobile devices. Journal of Computer Assisted Learning, 19(3), 260-272.

[29] Blikstein, P. (2011). Using learning analytics to assess students' behavior in open-ended programming tasks. Proceedings of the 1st International Conference on Learning Analytics and Knowledge (pp. 110-116).

[30] Chatti, M. A., et al. (2012). A reference model for learning analytics. International Journal of Technology Enhanced Learning, 4(5-6), 318-331.

[31] Baraniuk, R. G. (2008). Challenges and opportunities for the open education movement: A Connexions case study. Opening up Education: The Collective Advancement of Education through Open Technology, Open Content, and Open Knowledge, 229-246.

[32] Caswell, T., et al. (2008). Open content and open educational resources: Enabling universal education. The International Review of Research in Open and Distributed Learning, 9(1). 
[33] Fox, C. (2014). A guide to free and open source education. List of Open Education Resources Online. Retrieved, from the website: http://opensource.com/education/13/4/guide-open-source-education

[34] Nedic, Z., et al. (2003). Remote laboratories versus virtual and real laboratories. Frontiers in Education, 1.

[35] Ahn, J., et al. (2011). Social media access in K-12 schools: Intractable policy controversies in an evolving world. Proceedings of Am. Soc. Info. Sci. Tech., 48(1), 1-10.

[36] Halverson, R., \& Smith, A. (2009). How new technologies have (and have not) changed teaching and learning in schools. Journal of Computing in Teacher Education, 26(2), 49-54.

[37] Watson, W., et al. (2015). Education 3.0: Breaking the mold with technology. Interactive Learning Environments, 23(3), 332-343.

[38] Hew, K. F., \& Cheung, W. S. (2013). Use of web 2.0 technologies in K-12 and higher education: The search for evidence-based practice. Educational Research Review, 9, 47-64.

[39] Avidov-Ungar, O., \& Eshet-Alkalai, Y. (2011). Teachers in a world of change: Teachers' knowledge and attitudes towards the implementation of innovative technologies in schools. Interdisciplinary Journal of e-Learning and Learning Objects, 7(1), 291-303.

[40] Bebell, D., et al. (2004). Measuring teachers' technology uses. Journal of Research on Technology in Education, 37(1), 45-63.

[41] Barron, A., et al. (2003). Large-scale research study on technology in K-12 schools. Journal of Research on Technology in Education, 35(4), 489-507.

[42] Bauer, J., et al. (2005). Toward technology integration in the schools: Why it isn't happening. Journal of Technology and Teacher Education, 13(4), 519-546.

[43] Niemi, H., et al. (2013). Towards ICT in everyday life in Finnish schools: seeking conditions for good practices. Learning, Media and Technology, 38(1), 57-71.

[44] Topper, A., \& Lancaster, S. (2013). Common challenges and experiences of school districts that are implementing one-to-one computing initiatives. Computers in the Schools, 30(4), 346-358.

[45] Rideout, V. J., et al. (2010). Generation M [superscript 2]: Media in the lives of 8-to 18-year-olds. $A$ Kaiser Family Foundation Study.

[46] Rosen, L. D. (2011). Teaching the i-generation. Educational Leadership, 68(5), 10-15.

[47] Gronn, D., et al. (2014). Technological me': Young children's use of technology across their home and school contexts. Technology, Pedagogy and Education, 23(4), 439-454.

[48] Plowman, L., et al. (2008). Just picking it up? Young children learning with technology at home. Cambridge Journal of Education, 38(3), 303-319.

[49] Ash, K. (2012). Educators evaluate flipped classrooms. Education Week, 32(2), s6-s8.

[50] Borgen, J. (2013). Flip your school! systemic approaches to the schoolwide flipped classroom model. OnCUE Journal, 35(1), 17.

[51] Datig, I., \& Ruswick, C. (2013). Four quick flips activities for the information literacy classroom. Coll. Res. Libr. News. 74(5), 249-257.

[52] Tucker, B. (2012). The flipped classroom. Education Next, 12(1), 82-83.

[53] Fryer, W. (2005). The digital face of 21st-century curriculum. SMART Technologies Inc, 1(2), 48.

[54] Azer, S. A. (2005). The qualities of a good teacher: how can they be acquired and sustained?.J R Soc Med, 98(2), 67-69.

[55] McCombs, B. L. (2003). A framework for the redesign of K-12 education in the context of current educational reform. Theory into Practice, 42(2), 93-101.

[56] Scott, S., et al. Technology integration: The pedagogy of the 21st century. Proceedings of the Society for Information Technology \& Teacher Education International Conference, (pp. 1597-1601). 
[57] Wang, F., \& Hannafin, M. J. (2005). Design-based research and technology-enhanced learning environments. ETR\&D, 53(4), 5-23.

[58] Anderson, T. (2005). Design-based research and its application to a call centre innovation in distance education. Canadian Journal of Learning and Technology, 31(2).

[59] Fishman, B., et al. (2004). Creating a framework for research on systemic technology innovations. Journal of the Learning Sciences, 13(1), 43-76.

[60] Mee, A. (2007). E-learning funding for schools: A policy paradox? British Journal of Educational Technology, 38(1), 63-71.

[61] Claussen, J., \& Assad, M. J. (2010). Public expenditure tracking survey (PETS) for primary and secondary education in mainland Tanzania. The United Republic of Tanzania.

[62] GESCI. (2011). Teaching and learning science, mathematics and English in secondary schools using ICT in Tanzania. Global e-Schools and Communities Initiative (GESCI).

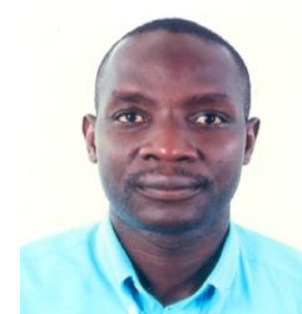

Patrick D. Kihoza was born in Tanzania. He is currently a PhD student at the Nelson Mandela African Institution of Sciences and Technology. He is majoring in information and communications sciences engineering (ICSE) in the School of Computational and Communication Sciences and Engineering. He graduated with a MSc. in computer science (international CBU master's programme in ICT) in 2012 from the University of Eastern Finland, Joensuu, Finland. He has a BSc. in information and communication technology management (BSc. ICTM) from Mzumbe University, Tanzania.

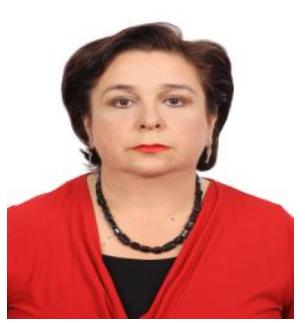

Irina Zlotnikova is a full professor and interim HOD computer science and software in College of ICT, Botswana International University of Science and Technology. She has a $\mathrm{PhD}$ in theory and methodology of computer science education (doctor of pedagogical sciences, Moscow, Russia). In addition she has a $\mathrm{PhD}$ in solid-state electronics, nano and microelectronics (Candidate of Technical Sciences, Voronezh, Russia) and an engineer degree in radiophysics and electronics (Voronezh, Russia).

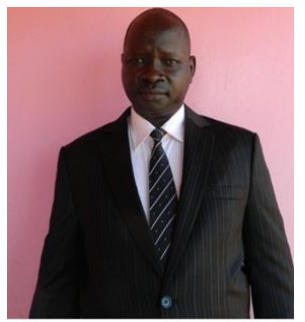

Joseph Kizito Bada is assistant professor and the head of Business Computing Department at Makerere University Business School, Kampala Uganda. He holds the $\mathrm{PhD}$ with computer Science major from University of Eastern Finland, Joensuu Campus. He studied the MSc in computer application technology at Hohai University Nanjing, People's Republic of China. He studied the BSc. mathematics, physics and education together with postgraduate diploma in computer science at Makerere University, Kampala Uganda. He is a researcher in ICT4D with focus on educational and medical informatics in developing countries. He has interest in rural development especially the care for education of children in primary schools and youth empowerment for development. He has ACM professional membership.

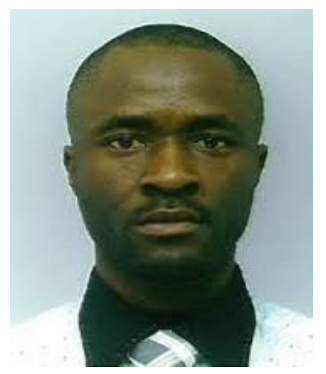

Khamisi Kalegele is a lecturer at the Nelson Mandela African Institution of Science and Technology, Arusha, Tanzania, School of Computational and Communication Sciences and Engineering. He received a $\mathrm{PhD}$ in information sciences, Tohoku University, Japan. Currently, he is undertaking R\&D activities related to ICT for development in health, education, and agriculture sectors. 